Revista de Metalurgia 52(3)

July-September 2016, e074

ISSN-L: 0034-8570

doi: http://dx.doi.org/10.3989/revmetalm.074

\title{
L10 ordered structures in Al-Cu-(Mg) alloys at the early stages of elevated temperature aging
}

\author{
Xia Fuzhong, Wang Mingpu ${ }^{\bowtie}$ \\ Central South University, School of Materials Science and Engineering, \\ 932 Lushan S Rd, Yuelu, 410083 Changsha, China \\ Corresponding author: wangmp@csu.edu.cn
}

Submitted: 23 November 2015; Accepted: 16 May 2016; Available On-line: 14 October 2016

\begin{abstract}
This study concerns the precipitation structures of $\mathrm{Al}-3 \mathrm{Cu}$ and $\mathrm{Al}-3 \mathrm{Cu}-1.78 \mathrm{Mg}$ (wt. \%) alloys at the early stages of elevated temperature aging. The $\mathrm{Al}-3 \mathrm{Cu}$ and $\mathrm{Al}-3 \mathrm{Cu}-1.78 \mathrm{Mg}$ alloys were solution treated at $540{ }^{\circ} \mathrm{C}$ and $500{ }^{\circ} \mathrm{C}$ for $2 \mathrm{~h}$, respectively, and then aged at $190^{\circ} \mathrm{C}$ for $2 \mathrm{~min}$. The precipitation structures in aged Al-3Cu- $(1.78 \mathrm{Mg})$ alloys were characterized by Transmission Electron Microscopy (TEM) and High Resolution Transmission Electron Microscopy (HTREM). 001 zone axis Selected area electron diffraction patterns indicate that L10 ordered structures are formed in the two aged alloys. HRTEM experiments reveal the partial dislocations on the interfaces of L10 ordered structures. From comparing experimental results with that in the literature, it is concluded that the $\mathrm{L} 10$ ordered structures in aged $\mathrm{Al}-3 \mathrm{Cu}$ alloy consist of $\mathrm{Al}$ and $\mathrm{Cu}$ atoms, and they are comprised by $\mathrm{Al}, \mathrm{Cu}$ and $\mathrm{Mg}$ atoms together in the aged $\mathrm{Al}-3 \mathrm{Cu}-1.78 \mathrm{Mg}$ alloy. On the basis of precipitate growing thermodynamics, it is thought the L10 ordered structures act as nuclei for GP zones in Al-Cu-(Mg) alloys during aging.
\end{abstract}

KEYWORDS: Aging; Aluminum alloys; Electron diffraction; High resolution electron microscopy; Ordered structure

Citation / Cómo citar este artículo: Fuzhong, X., Mingpu, W. (2016) "L10 ordered structures in Al-Cu-(Mg) alloys at the early stages of elevated temperature aging". Rev. Metal. 52(3):e074. doi: http://dx.doi.org/10.3989/revmetalm.074

RESUMEN: Estructuras ordenadas $\mathrm{L} 10$ en aleaciones $\mathrm{Al}-\mathrm{Cu}-(\mathrm{Mg})$ en los estados iniciales de envejecimiento a temperaturas elevadas. En este trabajo se estudian las estructuras de precipitación en $\mathrm{Al}-3 \mathrm{Cu}$ y $\mathrm{Al}-3 \mathrm{Cu}-1,78 \mathrm{Mg}$ ( $\%$ en peso) en los estados iniciales de envejecimiento a temperatura elevada. Las aleaciones $\mathrm{Al}-3 \mathrm{Cu}$ y Al-3Cu-1.78 Mg fueron sometidas a un tratamiento térmico de solución de $2 \mathrm{~h}$ a $540{ }^{\circ} \mathrm{C}$ y $500{ }^{\circ} \mathrm{C}$, respectivamente, y posteriormente envejecidas 2 min a $190^{\circ} \mathrm{C}$. Las estructuras de precipitación en Al-3Cu- $(1.78 \mathrm{Mg})$ envejecido fueron caracterizadas por microscopía electrónica de transmisión (TEM) y por microscopía electrónica de transmisión de alta resolución (HTREM). Los diagramas de difracción de electrones de área seleccionada indican que se forman estructuras ordenadas L10 en las dos aleaciones envejecidas. Experimentos de HRTEM revelan la presencia de dislocaciones parciales en las intercaras de las estructuras L10 ordenadas. Comparando estos resultados experimentales con la bibliografía, se concluye que la estructura ordenada L10 en Al-3Cu envejecido consiste de átomos de $\mathrm{Al}$ y $\mathrm{Cu}$, y en la aleación $\mathrm{Al}-3 \mathrm{Cu}-1.78 \mathrm{Mg}$ envejecida consisten de átomos de $\mathrm{Al}, \mathrm{Cu}$ y $\mathrm{Mg}$. Sobre la base de la termodinámica del crecimiento de los precipitados, se propone que la estructura ordenada L10 actúa como de nucleación de las zonas GP en las aleaciones $\mathrm{Al}-\mathrm{Cu}-(\mathrm{Mg})$ durante el envejecimiento.

PALABRAS CLAVE: Aleaciones de aluminio; Difracción de electrones; Envejecimiento; Estructura ordenada; Microscopía electrónica de alta resolución

Copyright: (C) 2016 CSIC. This is an open-access article distributed under the terms of the Creative Commons Attribution License (CC-by) Spain 3.0. 


\section{INTRODUCTION}

Precipitation-hardenable Aluminum alloys based on $\mathrm{Al}-\mathrm{Cu}-(\mathrm{Mg})$ compositions are widely used in structural aerospace applications due to their excellent mechanical properties. Many researches have been conducted to investigate the precipitation hardening mechanisms of the alloys. Especially in the past few years, the rapid hardening effect at the early stages of elevated temperature aging in $\mathrm{Al}-\mathrm{Cu}-\mathrm{Mg}$ alloys has attracted broad attention. For example, Atom Probe Tomography (APT) experiments have demonstrated the formation of "Cu-Mg" clusters in Al-Cu-Mg alloys at the early stages of artificial aging, which were believed to be responsible for the initial rapid age hardening of the alloys (Matsubara and Cohen, 1985; Kovarik et al., 2004) have affirmed the formation of L10 Ordered Structures (OS) at the early aging stages in the high $\mathrm{Mg}$ content $\mathrm{Al}-3 \mathrm{Mg}-0.4 \mathrm{Cu}-0.12 \mathrm{Si}$ (wt. \%) alloy by High Resolution Transmission Electron Microscopy (HRTEM). When it comes to the OS, it is worth noting the characteristic splitting of the supperlattice spots in associated Selected Area Electron Diffraction (SAED) patterns. Researches on the L10 OS in an $\mathrm{AuCu}$ alloy demonstrated that the strain at the OS interfaces can result in the splitting of supperlattice spots in SAED patterns into satellite spots (Ogawa et al., 1958; Glossop and Pashley, 1959). However in the work of Kovarik et al. (2004), the splitting of supperlattice spots was not taken into consideration in interpreting the HRTEM and SAED results of the $\mathrm{Al}-3 \mathrm{Mg}-0.4 \mathrm{Cu}-0.12 \mathrm{Si}$ alloy containing L10 OS. In addition, their hypothesis that the L10 OS in the alloy are comprised of $\mathrm{Mg}$ and $\mathrm{Cu}$ without $\mathrm{Al}$ deserves re-examination, because if the $\mathrm{Mg}$ atoms in their proposed model for L10 OS are replaced partially and randomly by $\mathrm{Al}$ atoms, their HRTEM and SAED results can still be explained. In the literature, whether or not OS are formed in both $\mathrm{Al}-\mathrm{Cu}$ and low $\mathrm{Mg}$ content $\mathrm{Al}-\mathrm{Cu}-\mathrm{Mg}$ alloys at the early stages of artificial aging has not yet been determined. Also there has been little research on the role of OS in the precipitation processes of Al-Cu-(Mg) alloys. Kovarik et al. (2004) considered $\mathrm{L} 10 \mathrm{OS}$ as GPI zones in the $\mathrm{Al}-3 \mathrm{Mg}-0.4 \mathrm{Cu}-0.12 \mathrm{Si}$ alloy. This study aims to address the above issues in Al-3Cu- $(1.78 \mathrm{Mg})$ alloys aged at $190{ }^{\circ} \mathrm{C}$ for $2 \mathrm{~min}$ by TEM and HRTEM experiments.

\section{MATERIALS AND METHODS}

$\mathrm{Al}-3 \mathrm{Cu}-(1.78 \mathrm{Mg})($ wt. \%) ingots were prepared by melting raw materials in a pit furnace under atmosphere. The raw materials used for melting were: $99.7 \%$ pure $\mathrm{Al}, 99.9 \%$ pure $\mathrm{Cu}$, and $99.9 \%$ pure $\mathrm{Mg}$. After melting, $\mathrm{Al}-\mathrm{Cu}$ ingots are homogenized at $530{ }^{\circ} \mathrm{C}$, and $\mathrm{Al}-\mathrm{Cu}-\mathrm{Mg}$ ingots at $490{ }^{\circ} \mathrm{C}$ for $24 \mathrm{~h}$. After homogenization the two alloys were hot rolled by $80 \%$ at $470{ }^{\circ} \mathrm{C}$, then $\mathrm{Al}-\mathrm{Cu}$ plates were solution treated at $540{ }^{\circ} \mathrm{C}$, and $\mathrm{Al}-\mathrm{Cu}-\mathrm{Mg}$ plates at $500{ }^{\circ} \mathrm{C}$ for $1 \mathrm{~h}$ and quenched into water. After quenching the two alloys were aged at $190{ }^{\circ} \mathrm{C}$ in a salt bath for 2 min. After aging TEM and HRTEM specimens were prepared by cutting a small piece from the aged samples, mechanically grinding to $60-80 \mu \mathrm{m}$ thickness and then jet polishing in a solution of 30 vol. \% $\mathrm{HNO}_{3}$ and 70 vol. $\% \mathrm{CH}_{3} \mathrm{OH}$ at $-20{ }^{\circ} \mathrm{C}$. TEM and HRTEM examination were performed using a JEM 2100 at $200 \mathrm{kV}$. TEM and HRTEM image processing were carried out using Gatan Digital Micro software and simulation of SAED patterns by Crystal Maker software.

\section{RESULTS AND DISCUSSION}

TEM images and corresponding 001 zone axis SAED patterns (insets of Fig. $1 \mathrm{a}-\mathrm{b}$ ) of aged $\mathrm{Al}-3 \mathrm{Cu}$ and $\mathrm{Al}-3 \mathrm{Cu}-1.78 \mathrm{Mg}$ alloys are shown in Fig. $1(\mathrm{a}-\mathrm{b})$, respectively. It can be seen a small number of lathlike particles (indicated by arrows) precipitate in both two aged alloys. It should be noted that in our
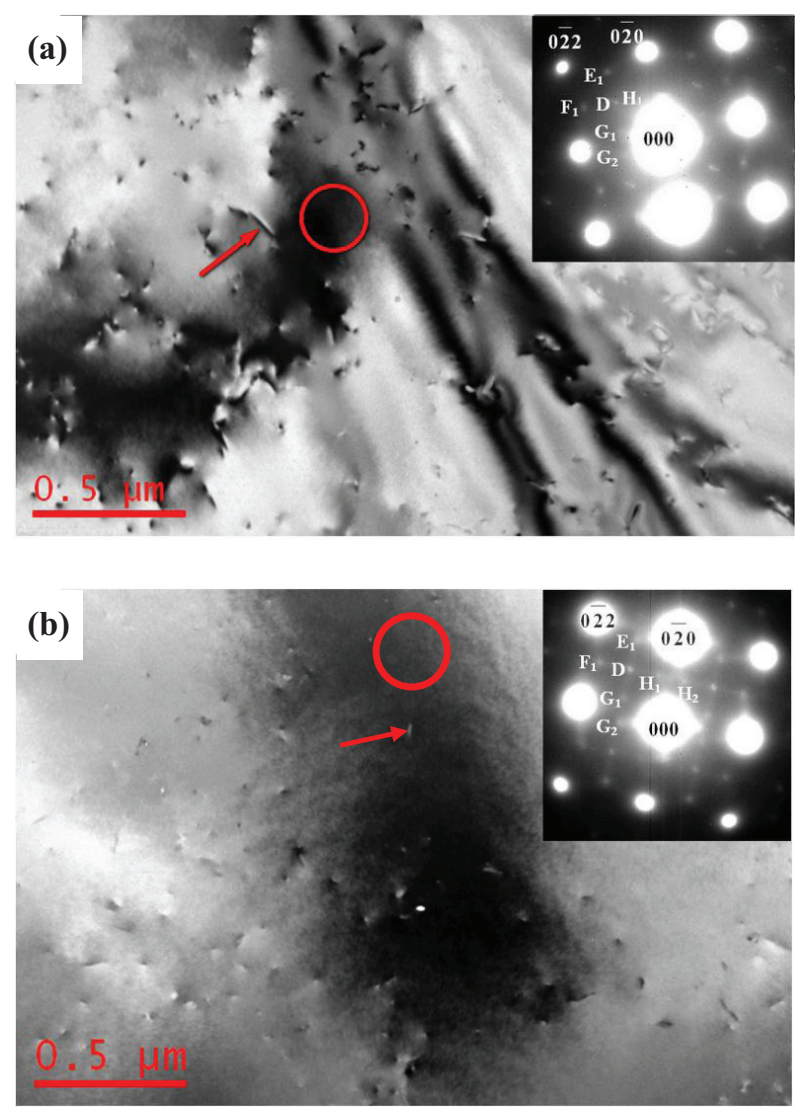

FIGURE 1. TEM imagines and corresponding 001 zone axis

SAED patterns of $\mathrm{Al}-3 \% \mathrm{Cu}$ : (a) $\mathrm{Al}-3 \% \mathrm{Cu}-1.78 \% \mathrm{Mg}$; and

(b) alloys aged at $190^{\circ} \mathrm{C}$ for $2 \mathrm{~min}$. Note that the SAED patterns come from the circled areas which are free of the lath-like particles arrowed in (a) and (b). Weak spots in the SAED patterns are labeled following the marking way in Fig. 2c. 
experiments regions as circled in Fig. 1 (a-b) which are free of visible particles were specially selected for SAED examinations. In addition to the lath-like particles, there seem to be smaller particles precipitated in the matrix of the two alloys as judged from the uneven contrast of the TEM bright field imagines in Fig. 1. In the SAED patterns of the circled regions in Fig. 1 (a-b) weak spots (labeled with letters) also suggest the presence of some precipitating structures in the matrix. But higher magnification TEM bright field and HRTEM observations have not revealed any precipitate within the circled areas selected for SAED experiments in Fig. 1 (a-b), which will be illustrated in the following. As will be demonstrated in latter analysis, the particle-like contrast of the circled areas in Fig. 1 (a-b) are caused by L10 OS, because chemical micro-inhomogeneity exists between ordered and disordered regions, which gives rise to the mass thickness contrast which looks like smaller precipitates. In addition, almost the same SAED patterns are obtained in Fig. 1 (a-b) for the two alloys, except that the diffraction intensities of these labeled weak spots are higher in the $\mathrm{Al}-\mathrm{Cu}-\mathrm{Mg}$ alloy. Among these weak spots, the $\{110\}$ supperlattice spots labeled D in Fig. 1 (a-b) are thought by Kovarik et al. (2004) to be caused by $\mathrm{L} 10 \mathrm{OS}$, which consist of $\mathrm{Mg}$ and $\mathrm{Cu}$ atoms in their $\mathrm{Al}-\mathrm{Mg}-\mathrm{Si}-\mathrm{Cu}$ alloy. The presence of $\{110\}$ supperlattice spots in Fig. 1a suggests that L10 OS are also formed in the aged Al-Cu alloy. The model we propose for L10 OS in Al-Cu alloy is shown in Fig. 2a, in which $\mathrm{Al}$ and $\mathrm{Cu}$ atoms occupy adjacent $\{002\} \mathrm{Al}$ planes. This model is consistent with Hardy's investigation (Hardy, 1951) on the aging of Al-Cu alloys which demonstrated that during aging $\mathrm{Cu}$ atoms initially precipitate on $\{002\} \mathrm{Al}$ planes. The simulated 001 zone axis SAED pattern of the Al-Cu alloy containing L10 OS is shown in Fig. 2b. Among these labeled spots in this pattern, the $\{110\}$ supperlattice spot D comes from the OS variants with $\{002\} \mathrm{Cu}$

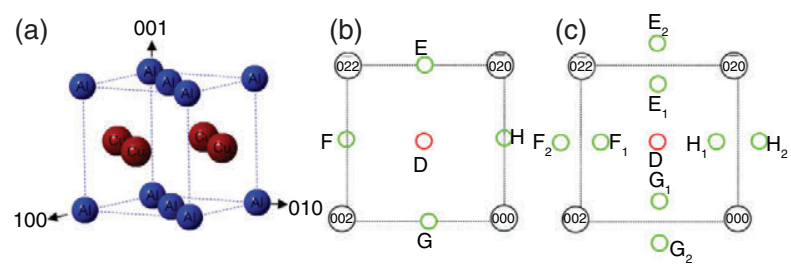

FIGURE 2. (a) The model for the L10 ordered structures in Al-Cu alloy; (b) simulated 001 zone axis SAED pattern of $\mathrm{Al}-\mathrm{Cu}$ alloy as three types of L10 OS variants in it are considered, in which the $\{110\}$ supperlattice spot D comes from the OS variants with $\{002\} \mathrm{Cu}$ planes perpendicular to the electron beam, and the supperlattice spots $\mathrm{E}, \mathrm{F}, \mathrm{G}$ and $\mathrm{H}$ are caused by the OS variants with $\{002\} \mathrm{Cu}$ planes

parallel to the electron beam; and (c) simulated 001 zone axis SAED pattern of Al-Cu alloy as the splitting of supperlattice diffractions by strained L10 OS interfaces is taken into account (see text for further explanation). planes perpendicular to the electron beam, spots $\mathrm{E}$ and $\mathrm{G}$ come from the $\mathrm{OS}$ variants with $\{002\}$ $\mathrm{Cu}$ planes parallel to the (0-20) plane, and $\mathrm{G}$ and $\mathrm{H}$ come from the OS variants with $\{002\} \mathrm{Cu}$ planes parallel to the (002) plane. By comparing this simulated SAED pattern with that in Fig. 1 (a-b), we can find only the $\{110\}$ supperlattice spots are present in experimental SAED patterns, other supperlattice spots labeled E, F, G and $\mathrm{H}$ in Fig. $2 \mathrm{~b}$ are absent in Fig. 1. Instead, some satellite spots labeled $E_{1}, F_{1}, G_{1}$ and $\mathrm{H}_{1}$ etc. (hereinafter denominated satellite spots) around the supperlattice locations E, F, G and $\mathrm{H}$ are caused in the SAED patterns of Fig. 1 (a-b), which is schematically illustrated in Fig. 2c.

In the following we will explore the origin of the satellite spots in the SAED patterns of Fig. 1 (a-b).

First it can be excluded that these satellite spots come from the lath-like particles arrowed in Fig. 1 (a-b), because regions as circled in Fig. 1 (a-b) which are free of any observable particles were specially selected for SAED examinations. In order to confirm this argument, both regions with and without lath-like particles in the two alloys are examined by HRTEM. Figure 3 shows the HRTEM and corresponding Fast Fourier Transform (FFT) results of aged $\mathrm{Al}-3 \mathrm{Cu}$ (Fig. $3 \mathrm{a}-\mathrm{c}$ ) and $\mathrm{Al}-3 \mathrm{Cu}-1.78 \mathrm{Mg}$ (Fig. 3 d-f) alloys. Among these images, (Fig. 3 b and e) show the FFT results of similar lath-like particles as arrowed in Fig. 1 (a-b), respectively, and Fig. 3 (c and f) show the FFT results of similar regions as circled in Fig. 1 (a-b), respectively. Comparing Fig. $3 b$ with Fig. 3c indicates the structure of the arrowed particle in Al-Cu alloy is the same as that of circled alloy matrix. This structure should be the L10 OS judged from the $\{110\}$ supperlattice spots in Fig. 3 (b-c). For the Al-Cu-Mg alloy, the FFT pattern in Fig. 3e indicates the lath-like particle arrowed in Fig. $1 \mathrm{~b}$ is $\mathrm{S}$ phase (Wang and Starink, 2005). In addition, the SAED pattern in Fig. 1b does not correspond to the simulated SAED pattern of S phase proposed by Wang and Starink (2005), meaning that these satellite spots in the SAED pattern of Fig. 1b have no relation to the lath-like particles which can be observed in the TEM bright field image. In the literature, the diffraction spots locating at the same positions as these satellite spots in Fig. $1 \mathrm{~b}$ are regarded by some authors from $\mathrm{S}$ " phase in Al-Cu-Mg alloys (Kovarik et al., 2004; Wang and Starink, 2004). However the presence of the same satellite spot distribution both in Fig. 1 (a-b) leads us to conclude that, in the present experiment, these satellite spots in Fig. 1 (a-b) come from the same precipitation products in $\mathrm{Al}-\mathrm{Cu}$ and $\mathrm{Al}-\mathrm{Cu}-\mathrm{Mg}$ alloys, and that should be the precipitation of $\mathrm{Cu}$ at the early aging stages of the two alloys. In Fig. 3c and $3 f\{110\}$ supperlattice spots are evident. In experiments, we have found this always the case, suggesting that L10 OS exist almost everywhere in the matrix of the two aged alloys. However, other 

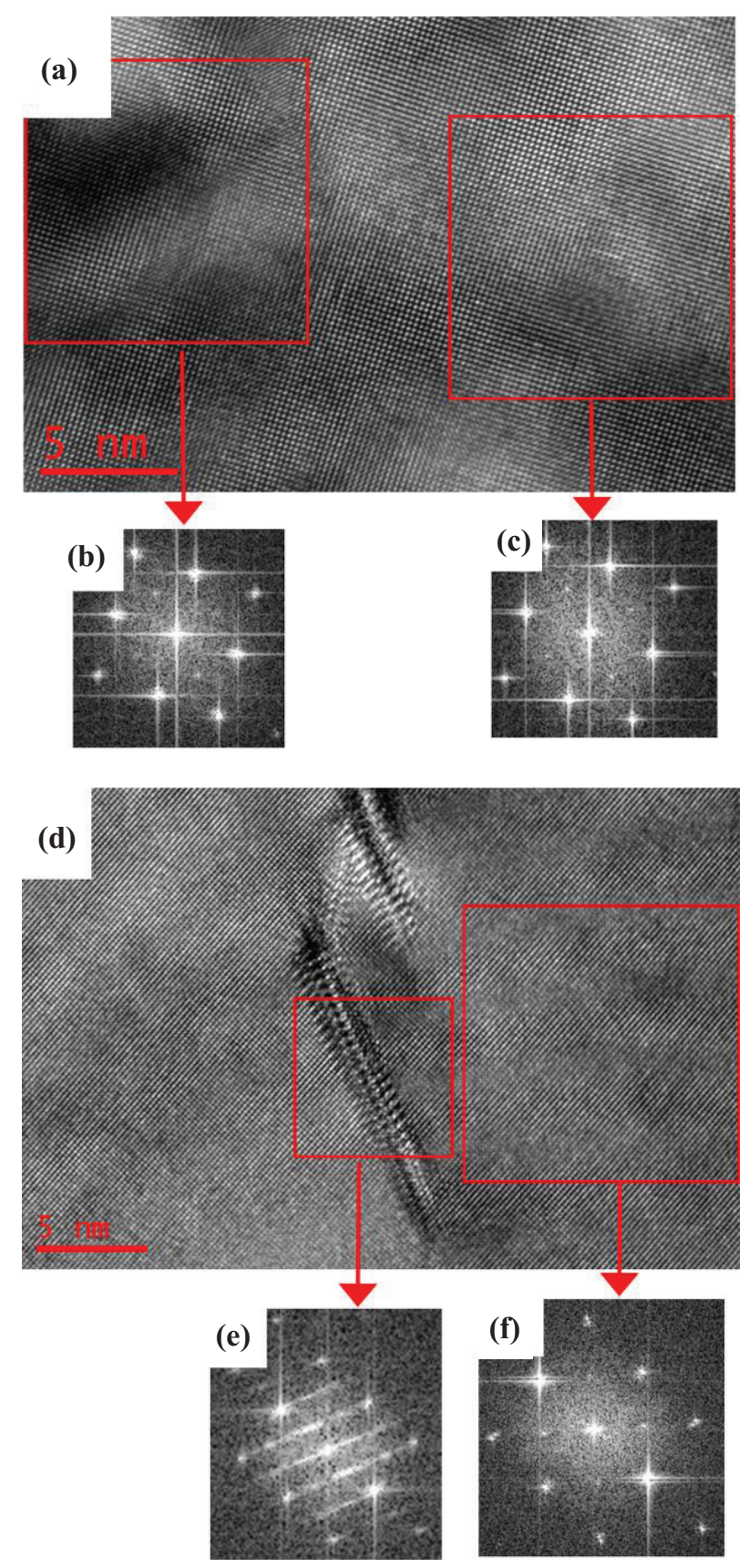

FIGURE 3. HRTEM micrographs and related fast Fourier transformation (FFT) images of $\mathrm{Al}-3 \mathrm{Cu}$ $(\mathrm{a}, \mathrm{b}, \mathrm{c})$ and $\mathrm{Al}-3 \mathrm{Cu}-1.78 \mathrm{Mg}(\mathrm{d}, \mathrm{e}, \mathrm{f})$ alloys aged at $190{ }^{\circ} \mathrm{C}$ for $2 \mathrm{~min}$. The FFT images in (b) and (e) come from the arrowed particles in Fig. 1 (a-b), respectively, and FFT images in (c) and (f) from the circled areas in Fig. 1 (a-b), respectively. In b, $\mathrm{c}$ and $\mathrm{f}$, except the fundamental diffractions, only

$\{110\}$ supperlattice spots can be seen.

supperlattice spots which should also be caused by L10 OS, such as the supperlattice spots E, F, G and $\mathrm{H}$ schematically shown in Fig. 2b, cannot be found in Fig. 3 (c and f), we will give our explanation to this puzzle in the following.
In the literature sometimes the same SAED patterns as shown in Fig. $1(\mathrm{a}-\mathrm{b})$ are attributed to the $\mathrm{Al}_{2} \mathrm{O}_{3}$ formed during TEM sample preparation (Phillips, 1975; Park and Ardell, 1983). But if this was the case, the same pattern should also present in the FFT graphs in Fig. 3 (c and f). In addition, we have found in the experiments if the Al-Cu-Mgalloy is overaged, the satellite spots in the SAED pattern will disappear, suggesting that these satellite spots in Fig. 1b come from specific precipitation products formed at the early aging stages. In view of the above arguments, we think these labeled weak spots in the SAED patterns of Fig. 1 (a-b) are caused by aging products other than oxides, which will be interpreted in the following.

It can also be excluded that the satellite spots in Fig. 1a and 1b come from the GP zones in the two alloys. GP zones in $\mathrm{Al}-\mathrm{Cu}-(\mathrm{Mg})$ alloys often take a lath-like morphology (Phillips, 1975; Ajika et al., 1985; Konno et al., 2001), but in this work we selected areas free of any obvious particle for SAED observations. In addition, it has been shown that in the 001 zone axis SAED patterns of aged Al-Cu$(\mathrm{Mg})$ alloys, GP zones give rise to intensity streaks passing through the fundamental spots in the $<001>$ direction (Gerold, 1988; Wang and Starink, 2005). But in the SAED patterns of Fig. 1 (a-b) no streak sign indicating the presence of GP zones can be found.

The presence of satellite spots in the SAED patterns of aged $\mathrm{Al}-\mathrm{Cu}-(\mathrm{Mg})$ can be interpreted taking into account the splitting of supperlattice diffractions from OS. As mentioned in the introduction, splitting of supperlattice diffractions often occurs when the first order supperlattice diffraction beams are diffracted again by strained interfaces of OS. In $\mathrm{Al}-\mathrm{Cu}-(\mathrm{Mg})$ alloy it has been shown that interfacial strains perpendicular to the $\{002\} \mathrm{Cu}$ planes exist at the precipitate interfaces as $\mathrm{Cu}$ atoms precipitate on $\{002\} \mathrm{Al}$ planes during aging (Ajika et al., 1985). Under conditions without the splitting of supperlattice diffractions, the L10 OS variants with $\{002\} \mathrm{Cu}$ planes parallel to electron beam should cause supperlattice spots E, F, G and H (illustrated in Fig. 2b) at $\{100\}$ positions in the 001 zone axis SAED pattern. However, under this condition, the strained interfaces of the OS variants are nearly parallel to the $\{100\}$ supperlattice diffractions, which will induces the secondary diffraction of expected $\{100\}$ supperlattice diffractions, making the expected $\{100\}$ supperlattice spots split in SAED patterns along $\{200\}$ directions which are perpendicular to the strained interfaces of OS. So satellite spots around the $\{100\}$ supperlattice diffractions as schematically shown in Fig. $2 \mathrm{c}$ are present in the experimental SAED patterns of Fig. $1(a-b)$. For the L10 OS variants with $\{002\} \mathrm{Cu}$ planes perpendicular to incident electron beam under the 001 zone axis, strained interfaces of the OS variants are nearly perpendicular to the 
$\{110\}$ supperlattice diffractions also, which keeps the $\{110\}$ supperlattice diffractions from being diffracted by the strained OS interfaces, so the $\{110\}$ ordered diffractions caused by this type of OS variants are present in Fig. 1 (a-b) without being split.

Because the satellite spots are caused by interfacial diffraction, a large area containing enough strained interfaces needs to be selected to result in visible diffraction intensities in SAED patterns and FFT images of HRTEM graphs. But in Fig. 3 (c and f) diffraction spots come from an area which is much smaller than that selected for SAED examinations in Fig. 1 (a-b), so the satellites spots visible in Fig. 1 (a-b) are covered by background noise in Fig. 3 ( $\mathrm{c}$ and f), although under bright-field TEM observations, the areas selected for FFT in Fig. 3 (c and f) look the same as that selected for SAED observations in Fig. 1 (a-b).

By choosing all the $\{110\}$ supperlattice spots in Fig. 3f to perform inverse fast Fourier transformation (IFFT), the $\{110\}$ plane projection image of Fig. 3f is obtained as shown in Fig. 4. In this figure, the local areas with clear lattice fringes are where the L10 OS locates. Except the L10 OS, some edge dislocations with one extra $\{220\}$ half-plane are also illustrated in Fig. 4. Because a perfect edge dislocation in fcc crystals contains two extra $\{220\}$ half-planes (Pan et al., 1998), the edge dislocations illustrated in Fig. 4 are not the perfect edge dislocations. It has been shown in the literature partial dislocations often exist at the OS interfaces (Glossop and Pashley, 1959).

The L10 OS in Al-3Mg-0.4Cu-0.12Si alloy were considered by Kovarik et al. (2004) to be comprised

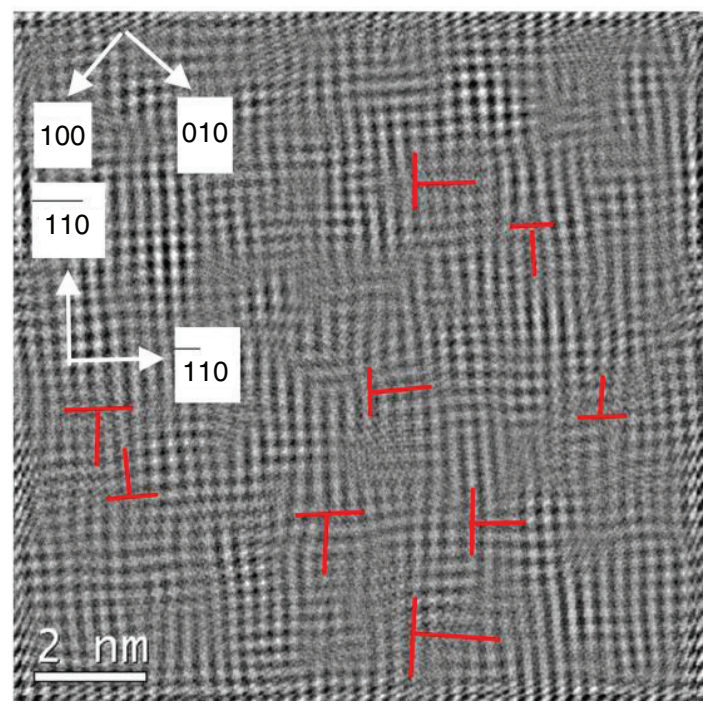

FIGURE 4. $\{110\}$ plane projection image of Fig. $3 \mathrm{f}$ obtained by choosing all the $\{110\}$ supperlattice spots in Fig. 3f to perform inverse fast Fourier transformation. Related projected directions of crystalline planes and some partial dislocations with one extra $\{220\}$ half-plane and are illustrated. of $\mathrm{Mg}$ and $\mathrm{Cu}$ atoms without $\mathrm{Al}$ (Kovarik et al., 2004). However, APT experiments have indicated that $\mathrm{Cu}-\mathrm{Mg}$ clusters formed in $\mathrm{Al}-\mathrm{Cu}-\mathrm{Mg}$ alloys at the early stages of artificial aging contain considerable $\mathrm{Al}$ atoms (Marceau et al., 2010). Between the SAED patterns in Fig. 1 (a-b), except the higher diffraction intensities from $\mathrm{L} 10 \mathrm{OS}$ in the $\mathrm{Al}-\mathrm{Cu}-\mathrm{Mg}$ alloy, no other differences can be identified. This means that in $\mathrm{Al}-\mathrm{Cu}-\mathrm{Mg}$ alloy $\mathrm{Mg}$ can promote the formation of L10 OS during aging without changing the precipitation structure shown in Fig. 2a. So we conclude that the $\mathrm{L} 10 \mathrm{OS}$ in $\mathrm{Al}-\mathrm{Cu}-\mathrm{Mg}$ alloy are comprised of $\mathrm{Al}, \mathrm{Cu}$ and $\mathrm{Mg}$ atoms, with $\mathrm{Mg}$ randomly replacing some $\mathrm{Al}$ atoms in the model shown in Fig. 2a. The higher Mg content in the alloy is the more $\mathrm{Al}$ atoms in OS will be replaced by $\mathrm{Mg}$.

At last we shall make some comments on the relationship between the L10 OS and GP zones in $\mathrm{Al}-\mathrm{Cu}-(\mathrm{Mg})$ alloys. As has already been discussed earlier, the L10 OS are not GP zones. They have no clear morphologies in both bright-field TEM and HRTEM images as shown in Fig. 1 and Fig. 3, respectively. We think the L10 OS can be regarded as nuclei for GP zones. This proposition means that the precipitation processes in $\mathrm{Al}-\mathrm{Cu}-(\mathrm{Mg})$ alloys begin with gradual enrichment of $\mathrm{Cu}$ atoms on $\{002\} \mathrm{Al}$ planes, generating the L10 OS at the same time. At the early stage of their growth, the L10 OS grow up in all directions to an irregular or globular shape by increasing and enlarging the $\{002\} \mathrm{Cu}$ plane layers within them, and interfacial strains perpendicular to the $\{002\} \mathrm{Cu}$ planes at the OS interfaces increase gradually with their growth. As the OS grows to a critical size, the interfacial strains are so large that lath-like shape will be the most favorable morphology for L10 OS to take in order to decrease the elastic interfacial strain and grow continually. This means that not all $\{002\} \mathrm{Cu}$ planes already formed in OS can keep growing out along the $\{002\} \mathrm{Al}$ planes. That most likely to occur is only one layer of $\{002\}$ $\mathrm{Cu}$ plane can keep growing out, bringing about GPI zones. Next with more $\mathrm{Cu}$ atoms diffusing from surrounding matrix into the GPI zones, another $\{002\}$ $\mathrm{Cu}$ plane can grow out also, bringing about GPII zones. So we propose the decomposition processes of $\mathrm{Al}-\mathrm{Cu}-(\mathrm{Mg})$ alloys during artificial aging as follows: solid solution $\rightarrow$ L10 OS $\rightarrow$ GPI zones $\rightarrow$ GPII zones $\rightarrow \theta^{\prime}\left(\mathbf{S}^{\prime}\right) \rightarrow \theta(\mathrm{S})$. The multi-layer GPI zones reported by some authors in the literature may be the L10 OS which have not yet grown to the critical size to evolve into GPI zones (Matsubara and Cohen, 1985; Höno et al., 1986).

\section{CONCLUSIONS}

The formation of L10 OS is the mutual precipitation processes occurring at the early stages of elevated temperature aging in $\mathrm{Al}-\mathrm{Cu}$ and $\mathrm{Al}-\mathrm{Cu}-\mathrm{Mg}$ alloys. 001 zone axis SAED patterns of the two alloys 
can be interpreted by taking into account the existence of L10 OS and electron diffraction on strained interfaces of L10 OS. L10 OS in Al-Cu-Mg alloy are comprised of $\mathrm{Al}, \mathrm{Cu}$ and $\mathrm{Mg}$ atoms together. The decomposition processes of $\mathrm{Al}-\mathrm{Cu}-(\mathrm{Mg})$ alloys begin with the formation of L10 OS, from which GPI zones develop in order to minimize interfacial strains.

\section{REFERENCES}

Ajika, N., Endoh, H., Hashimoto, H., Tomita, M., Yoshida, H. (1985). Interpretation of atomic-resolution electron microscope images of Guiner-Preston zones in aluminium-copper alloys. Philos. Mag. A 51 (5), 729-744. http://dx.doi. org/10.1080/01418618508245284.

Gerold, V. (1988). On the structures of Guinier-Preston zones in Al-Cu alloys introductory paper. Scripta Metall. 22 (7), 927-932. http://dx.doi.org/10.1016/S0036-9748(88)80077-2.

Glossop, A.B., Pashley, D.W. (1959). The direct observation of anti-phase domain boundaries in ordered Copper-Gold (CuAu) alloy. P. Roy. Soc. A-Mat. Phy. 250 (1260), 132-146. http://dx.doi.org/10.1098/rspa.1959.0056.

Höno, K., Satoh, T., Hirano, K. (1986). Evidence of multi-layer GP zones in Al-1.7at.\% Cu alloy. Philos. Mag. A 53 (4), 495-504. http://dx.doi.org/10.1080/01418618608242848.

Hardy, H.K. (1951). The ageing characteristics of binary Aluminium-Copper Alloys. J. Inst. Met. 79, 321-369.

Konno, T.J., Hiraga, K., Kawasaki, M. (2001). Guinier-Preston (GP) zone revisited: atomic level observation by HAADFTEM technique. Scripta Mater. 44 (8-9), 2303-2307. http:// dx.doi.org/10.1016/S1359-6462(01)00909-5.
Kovarik, L., Gouma, P.I., Kisielowski, C., Court, S.A., Mills, M.J. (2004). A HRTEM study of metastable phase formation in $\mathrm{Al}-\mathrm{Mg}-\mathrm{Cu}$ alloys during artificial aging. Acta Mater. 52 (9), 2509-2520. http://dx.doi.org/10.1016/j. actamat.2004.01.041.

Marceau, R.K.W., Sha, G., Ferragut, R., Dupasquier, A., Ringer, S.P. (2010). Solute clustering in $\mathrm{Al}-\mathrm{Cu}-\mathrm{Mg}$ alloys during the early stages of elevated temperature ageing. Acta Mater. 58 (15), 4923-4939. http://dx.doi. org/10.1016/j.actamat.2010.05.020.

Matsubara, E., Cohen, J.B. (1985). The G.P. zones in Al-Cu alloys-II. Acta Metall. 33 (11), 1957-1969. http://dx.doi. org/10.1016/0001-6160(85)90118-X

Ogawa, S., Watanabe, D., Watanabe, H., Komoda, T. (1958). The direct observation of the long period of the ordered alloy $\mathrm{CuAu}(\mathrm{II})$ by means of electron microscope. Acta Crystallogr. 11, 872-875. http://dx.doi.org/10.1107/ S0365110X58002462.

Pan, J.S., Tong, J.M., Tian, M.B. (1998). Fundamentals of Materials Science, TsingHua University Press, Beijing.

Park, J.K., Ardell, A.J. (1983). Microstructures of the commercial $7075 \mathrm{Al}$ alloy in the T651 and T7 tempers. Metall. Trans. A 14 (10), 1957-1965. http://dx.doi.org/10.1007/ BF02662363.

Phillips, V.A. (1975). High resolution electron microscope observations on precipitation in Al-3.0\% Cu alloy. Acta Metall. 23(6), 751-767. http://dx.doi.org/10.1016/0001-6160(75)90058-9.

Wang, S.C., Starink, M.J. (2004). The assessment of GPB2/S" structures in Al- $\mathrm{Cu}-\mathrm{Mg}$ alloys. Mat. Sci. Eng. A-struct 386 (1-2), 156-163. http://dx.doi.org/10.1016/j. msea.2004.07.006.

Wang, S.C., Starink, M.J. (2005). Precipitates and intermetallic phases in precipitation hardening $\mathrm{Al}-\mathrm{Cu}-\mathrm{Mg}-(\mathrm{Li})$ based alloys. Int. Mater. Rev. 50 (4), 193-215. http://dx.doi. org/10.1179/174328005x14357. 